\title{
FERTILITY, MORTALITY, AND THE DEVELOPED WORLD'S DEMOGRAPHIC TRANSITION
}

\author{
HANS FEHR \\ SABINE JOKISCH \\ LAURENCE J. KOTLIKOFF
}

CESIFO WORKING PAPER NO. 1326

CATEGORY 1: PUBLIC FINANCE

NOVEMBER 2004

Presented at CESifo Venice Summer Institute, Workshop ON

Policy ANALYSIS With NuMERICAL MODELS, JULy 2004

\footnotetext{
An electronic version of the paper may be downloaded

- from the SSRN website:

www.SSRN.com

- from the CESifo website:

www.CESifo.de
} 


\title{
FERTILITY, MORTALITY, AND THE DEVELOPED WORLD'S DEMOGRAPHIC TRANSITION
}

\begin{abstract}
This study uses Fehr, Jokisch, and Kotlikoff's (2004a) dynamic general equilibrium model to analyze the effects of changes in fertility and mortality on the developed world's demographic transition. The model features three regions - the U.S., Japan, and the EU-15 - and incorporates age- and time-specific fertility and mortality rates, detailed fiscal institutions, and international capital mobility, subject to adjustment costs. Our simulations confirm the offsetting fiscal and economic consequences of both higher fertility and lower mortality rates. The simulations indicate very minor effects on the developed world's rather bleak baseline transition path from either major increases in fertility rates or major reductions in mortality rates.
\end{abstract}

JEL Code: D58, H55, J11.

Keywords: demographic transition, computable general equilibrium model (CGE), fertility, mortality.

Hans Fehr
University of Wuerzburg
Department of Economics
Sanderring 2
97070 Wuerzburg
Germany
hans.fehr@mail.uni-wuerzburg.de sabine.jo
Laurence J. Kotlikoff
Boston University
Department of Economics
270 Bay State Road
Boston, MA 02215
USA
kotlikof@bu.edu

Research support by the Deutsche Forschungsgemeinschaft (grant: FE 377/4-2), the National Institute of Aging, the Smith Richardson Foundation, and Boston University is gratefully acknowledged. We would like to thank Charles Horioka, Bernd Raffelhüschen and Reinhold Schnabel for providing data on wealth, population and health care. 


\section{Introduction}

As is well known, postwar changes in fertility and mortality rates are leading to an unprecedented aging of the developed world. By mid-century roughly half of all Japanese and Europeans will be older than 50 and half of Americans will be older than 42. The projected rise in dependency rates portends major increases in payroll and other tax rates. This paper explores the roles of fertility and mortality in altering fiscal and economic performance over the short, medium, and long runs. Our key goal is understanding whether higher fertility or higher mortality could significantly ameliorate the pending old-age fiscal crisis.

As a rule, fertility and mortality rates in developed countries are very low. But there is remarkable heterogeneity in these rates across first-world countries. In the U.S., for example, the current fertility rate is very close to the 2.1 rate needed, absent immigration, to replace the population. In Italy, in contrast, the current rate is only 1.2! At this rate, Italy can look forward to a 28 percent smaller population in 2050. While Italy has the lowest fertility rate in the pre-merger EU (EU-15), almost all of its fellow member states, including France, Spain, and Germany, are projected to depopulate over this century. Japan is in the same boat. Unless things change, it will shed a quarter of its population by mid century.

The striking low fertility rates in the EU and Japan are hard to believe. They are even harder to accept as permanent. This explains why the OECD, the United Nations (see UNPD, 2003), and individual governments foresee, albeit with little justification, major fertility rebounds in the near term.

Life expectancy has increased steadily in the developed world, but starting from different levels and progressing at different rates. Between 1950 and 2000 U.S. life expectancy (for both sexes combined) rose by 7.3 years (from 69.9 to 76.2 years). Over the same period the respective Japanese and Western European lifespan expansions rose by 16.6 years (from 63.9 to 80.5) and 10.1 years (from 67.6 to 77.7 ), see UNPD (2003). These longevity increases arose primarily because of improvements in survival after age 65 .

Today's demographers are engaged in an intense debate about the future course of longevity. Some think it will continue to rise, while others think it will reach a natural limit (see Oeppen and Vaupel, 2002). The United Nations projections take an intermediate position. They assume that life expectancy will rise through 2050, but at half the rate experienced over the second half of the 20th Century.

Our goal is understanding how future changes in fertility and mortality rates will alter future economic and fiscal conditions. Theory alone provides no clear answers. Take a rise in fertility rates. Such a change increases the number of future tax payers and, thereby, generates more future revenues. But it also increases public education and health expenditures and other child-specific government outlays. Since fiscal systems and conditions are quite different across countries, it isn't clear whether the short-run fiscal costs of more children exceed, equal, or fall short of the long-run fiscal benefits. Nor is there a definitive empirical answer to this question. Indeed, previous research on the fiscal and economic effects of fertility changes is quite limited ${ }^{1}$.

\footnotetext{
${ }^{1}$ Cutler, et. al. (1990) argue that lower fertility would have a positive economic impact in the U.S. by
} 
Turning to reductions in mortality rates, we know that increased longevity spells higher total benefit payments to current and future elderly. As Lee and Skinner (1999) stress, this implies a higher fiscal burden and, generally speaking, less saving and capital formation. But lifespan extension should also lead people to save more for their longer projected retirements. Bloom, et. al. (2003) provide empirical support for this view. On the other hand, Skinner (1985) argues that rising longevity will reduce savings if bequests are purely altruistic and annuity markets are incomplete.

The present paper aims to improve our understanding of the interaction between demographic changes and economic outcomes. The framework for our analysis is an updated version of the three-region dynamic life-cycle simulation model developed in Fehr, Jokisch, and Kotlikoff (2004a, b). The three regions are the U.S., Japan, and the EU. There is a single good that can either be consumed or invested at home or abroad; i.e., there is international capital mobility. In contrast to capital, labor is not mobile internationally, and immigration to each region is exogenous. The model has been updated to incorporate the UNPD's (2003) medium baseline population projections as well as the latest fiscal indicators. Our baseline simulations are bearers of bad news. They generate major tax hikes to pay the elderly their benefits, a significant capital shortage, a reduction in pre-tax wages of roughly 20 percent, and an increase in the world interest rate of 50 percent. These baseline simulation results are predicated on the UNPD assumption that fertility rates in the U.S., Japan, and the EU quickly and permanently return to levels consistent with zero population growth. For the U.S. this means a modest decline in fertility below the current roughly 2.1 rate in order to offset the country's high rate of immigration. For Japan and the EU, this means a major rise in fertility rates.

What would happen were current fertility rates to persist for the next half century and, only then, revert to ZPG-consistent levels? The answer, in the case of the U.S., is lower payroll tax rates, but higher income tax rates; i.e., less fiscal pressure on the social security system, but more fiscal pressure on the rest of the government's budget due to the need to pay for more schooling and other needs of children. Exactly the opposite happens in the EU and Japan. But the key lesson learned from these simulations is not what changes, but what doesn't change. The overall economic and fiscal impacts of these quite significant fertility changes are surprisingly small and take a long time to materialize. The dog also fails to bark in our simulations of significant reductions in mortality rates. These simulations generate no major economic or fiscal effects.

We proceed by discussing the model's structure, detailing its calibration, presenting its baseline simulation, and then assessing the effects on the demographic transitions of the three regions of deviations from baseline fertility and mortality rates.

inducing a higher rate of technological progress. Guest and McDonald (2002) analyze the economic consequences of declining birth rates for Australia and conclude that future living standards are positively affected. Heijdra and Ligthart (2004) find that a drop in the fertility rate decreases the per capita capital stock and increases per capita consumption. And Berkel, et. al. (2004) show that higher fertility rates would improve the long-run finances of German's pension system. 


\section{The Structure of the World Economy ${ }^{2}$}

Our model builds on Auerbach-Kotlikoff's (1987) overlapping generation (OLG) model, which also simulates demographic transitions by specifying an exogenous population projection for a fixed number of years followed by ZPG birth rates and stable death rates. Kotlikoff, Smetters, and Walliser (2001) extended this approach for the U.S. by incorporating age-specific fertility, lifespan extension, intergenerational earnings heterogeneity, and additional fiscal institutions. Fehr, Jokisch and Kotlikoff (2004a, b) included lifespan uncertainty as well as bequests arising from incomplete annuitization. They also introduced multiple regions with international capital mobility and immigration. As in Kotlikoff, Smetters, and Walliser (2001), our model features monozygotic reproduction with agents in their child-bearing years giving birth each year to fractions of children. This means of finessing actually marriage and family formation permit us to incorporate changes through time in age-specific fertility rates and to line up our model's age-specific population counts closely to those forecast for the three regions.

We assume that agents care about their children's utility when they are young and make consumption expenditures on behalf of their children in accordance with these preference. We also assume that agents die with realistic mortality probabilities starting at age 68. Agents fully appreciate the uncertainty of their longevities and maximize, at any point in time, their expected remaining lifetime utilities. The inclusion of lifespan uncertainty permits a realistic modeling of bequests and inheritances. We generate bequests by assuming, realistically, that agents fail to annuitize their assets in old age. Hence, when they die, they leave undesired bequests to their children ${ }^{3}$. Since agents die at different ages and have children of different ages, their heirs also inherit at different ages. Older heirs who were born when their parents were young receive inheritances later in their life than do their younger siblings. Finally, uninsurable lifespan uncertainty also leads to a gradual decline in consumption in old age. This is another important feature of actual longitudinal age-consumption profiles.

Our model includes capital adjustment costs. As is well known, these costs can drive temporary wedges between the marginal products of capital in different regions and lead the market values of capital assets to temporarily differ from their replacement costs. Thus inclusion of adjustment costs in the model generates what amounts to regional stock markets and permits us to explore how population aging affects stock prices through time.

A final key feature of our framework is its intra-cohort disaggregation. As in Kotlikoff, Smetters and Walliser (2001), we distinguish three income classes within each generation each with its own earnings ability. Immigrants are also split into these income classes permitting us to simulate the arrival of immigrants with different stocks of human and physical capital.

The following sections present the general structure of our model. A more detailed description is provided in Fehr et. al. (2003).

\footnotetext{
${ }^{2}$ This section draws heavily on Fehr, Jokisch and Kotlikoff (2004a, b).

${ }^{3}$ This treatment of bequests finds support in a recent study by Gokhale, Kotlikoff, Sefton, and Weale (2001), which shows that undesired bequests can explain both the level, Gini coefficient, and skewness of wealth in the U.S.
} 


\section{Demographics}

Each region is populated by households who live at most to age 90. Consequently, there are 91 generations with surviving members at any point in time. The individual life cycle of a representative agent is described in Figure 1. Between ages 0 and 20 our agents are children who earn no money and are supported by their parents. At age 21 our agents leave their parents and go to work. Between ages 23 and 45 our agents give birth to fractions of children at the beginning of each period, i.e. the first (fraction of) children are born when the agents are 23 and the last are born when they are age 45. An agent's first-born children (fractions of children) leave home when the parents are age 43 , while the last-born leave when the agents are age 66. Our agents die between ages 68 and 90. The probability of death is 1 at age 91 . Children always outlive their parents, meaning that parents always outlive grandparents. To see this note that if a parent reaches age 90 , his or her oldest children will be 67 . These are children who were born when the parent was age 23 .

Figure 1: The individual life-cycle

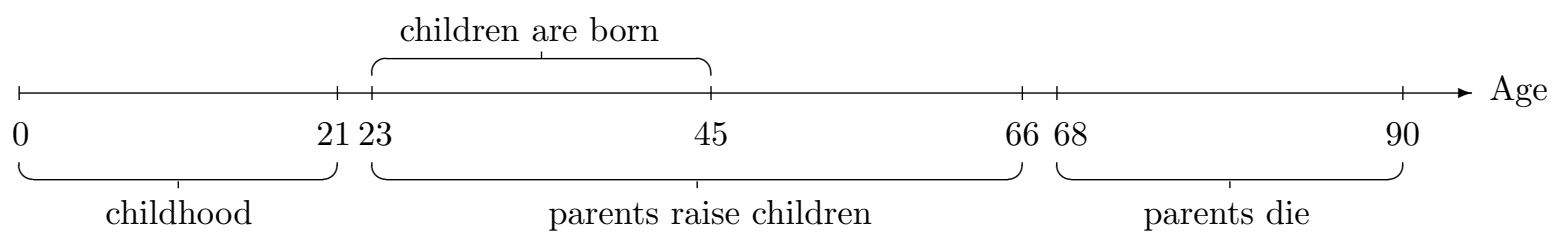

In each year new immigrants in each skill and age group arrive with the same number and age distribution of children and the same level of assets as natives of the identical skill and age. Since the demographic structure has the same form in all three regions, it suffices to discuss a representative region and omit region indices.

To specify the current and future demographic structure of each region we start with the year-2000 age-specific population $[\bar{N}(a, 2000)]$ and age-specific net-immigration $[\overline{N M}(a, 2000)]$ counts.

In constructing existing as well as future age-population counts, we have to link each initial cohort between the ages of 1 and 68 to those of their parents who are still alive. The reason is that children receive bequests from their parents and the levels and timing of these inheritances depend on the ages of their parents. This linkage is achieved by applying past fertility rates to each cohort under age 69 in year 2000. If, for example, 15 percent of the parents of newborns in 1980 were 25 years old, then 15 percent of the 20-year-old's in year 2000 are assigned to parents age 45. In addition, each cohort is split into three income classes $k$. Specifically, we assume that 30 percent of each cohort belong to the lowest income class, 10 percent to the top income class, and the remaining 60 percent to the middle income class. Formally, we denote the final population vector for year 2000 as $N(a, 2000, s, k)$ where $a=$ $1, \ldots, 90, s=23, \ldots, 45, k=1,2,3$. The term $s$ references the age of the parent at the time of birth of agents age $a$ in 2000 .

To determine the evolution of the population in each region over time, we applied regionand age-specific mortality $[d(a, i)]$ and birth rates to the cohorts alive in year 2000 as well 
as to their children as they reach their ages of fertility and mortality. In the baseline path the exogenous current and future mortality and fertility rates follow the medium variant of the latest United Nations population projections (UNPD, 2003). Consequently, mortality is decreasing in all three regions until 2050, but the Japanese have a significantly higher life expectancy than do Americans or EU citizens. Figure 2 shows our agent's life expectancies at birth in the baseline path which is kept constant after year 2050. The respective numbers are higher than the actual values, since our model's agents don't die prior to age 68. However, the model's life expectancies conditional on reaching age 60 are close to those reported by the UNPD (2003).

Figure 2: Life expectancy

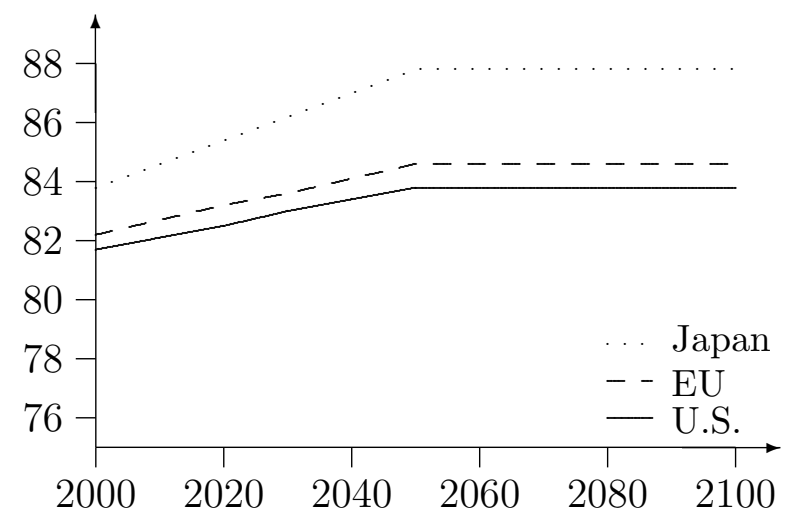

Figure 3: Total fertility (birth per woman)

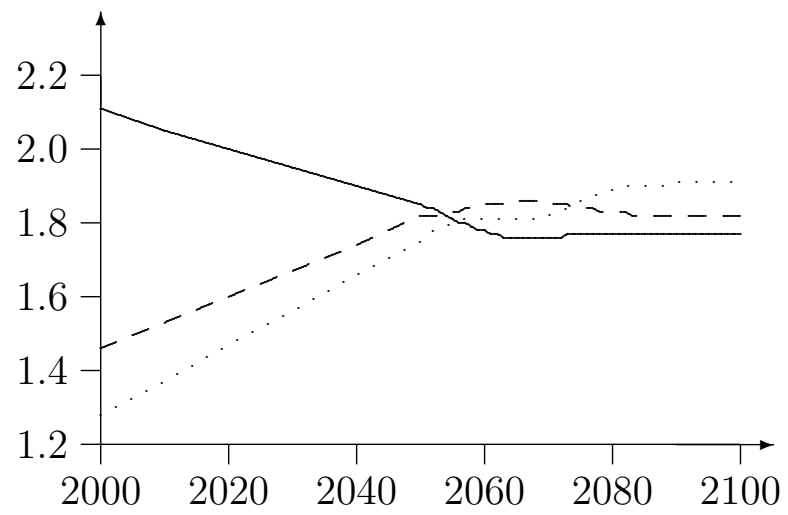

Total fertility rates currently equal 2.1, 1.3, and 1.5 in the U.S., Japan, and the EU, respectively. Nevertheless the United Nations expects fertility rates in all three regions to converge to 1.85 children by 2050. This path of fertility rates is shown in Figure 3 . In the baseline path, we assume annual net immigration of 1 million per year in the U.S., 450,000 in the EU, and 54,000 in Japan. Given the population age structure in year 2000 as well as projected future fertility, mortality, and net immigration rates, we compute the population vector $N(a, t, s, k)$ for the years $t$ between 2001 and 2050. After year 2050, fertility rates are endogenously adjusted in order to achieve zero population growth and a stable population age structure. Since net immigration is positive, the required fertility rates are below 2.0.

The straight lines in Figures 4 and 5 report the resulting change in the total population and the dependency ratio. Due to high fertility and net immigration rates, the U.S. population is projected to increase from 275 million in 2000 to 442 million in 2100. In Europe, the population falls over the century from 375 to 340 million. And in Japan, the population falls from 126 million to just 85 million! As one would expect, dependency ratios are increasing in all three regions through 2050. However, the three regions experience important differences in the aging of their populations. First, the increase in the dependency ratio is much greater in Japan and Europe than in the U.S. Second, dependency ratios fall in Europe and Japan after peaking in year 2050, while they remain roughly stable after 2030 in the U.S.

Figures 4 and 5 also show the consequences of alternative fertility and mortality assumptions. If fertility in the U.S. remains at its currently relatively high level through 2050, the 
Figure 4: Total population (in mio.)

Figure 5: Dependency ratio (60-90/20-59)

(a) U.S.
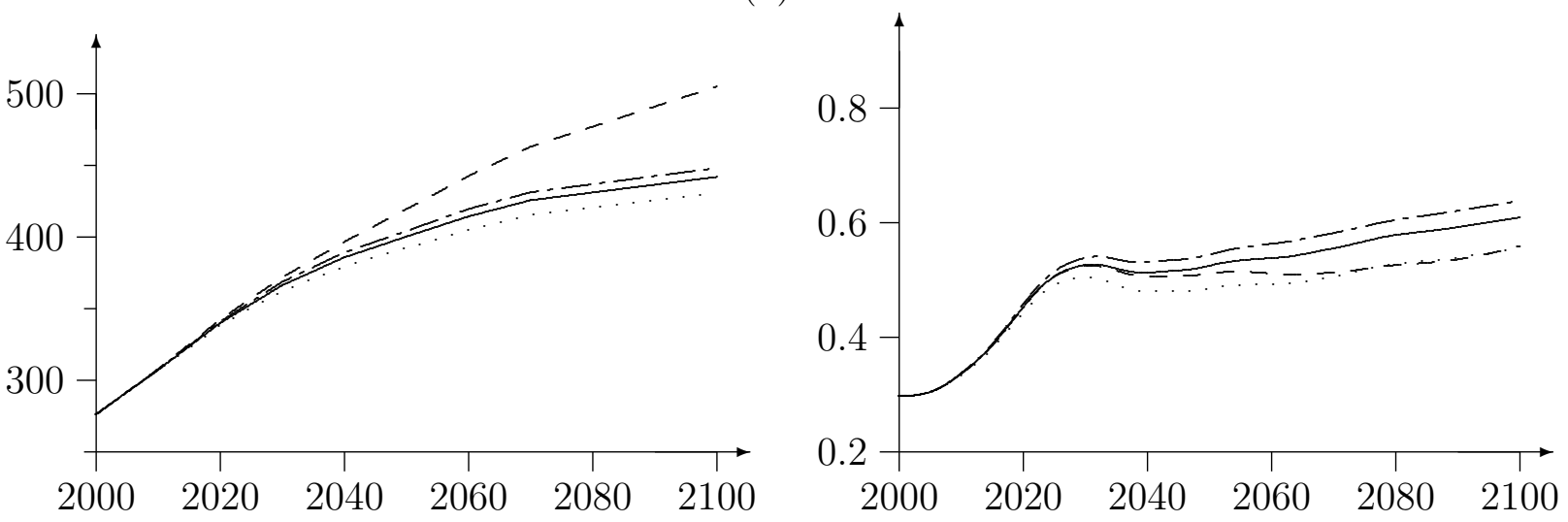

(b) EU
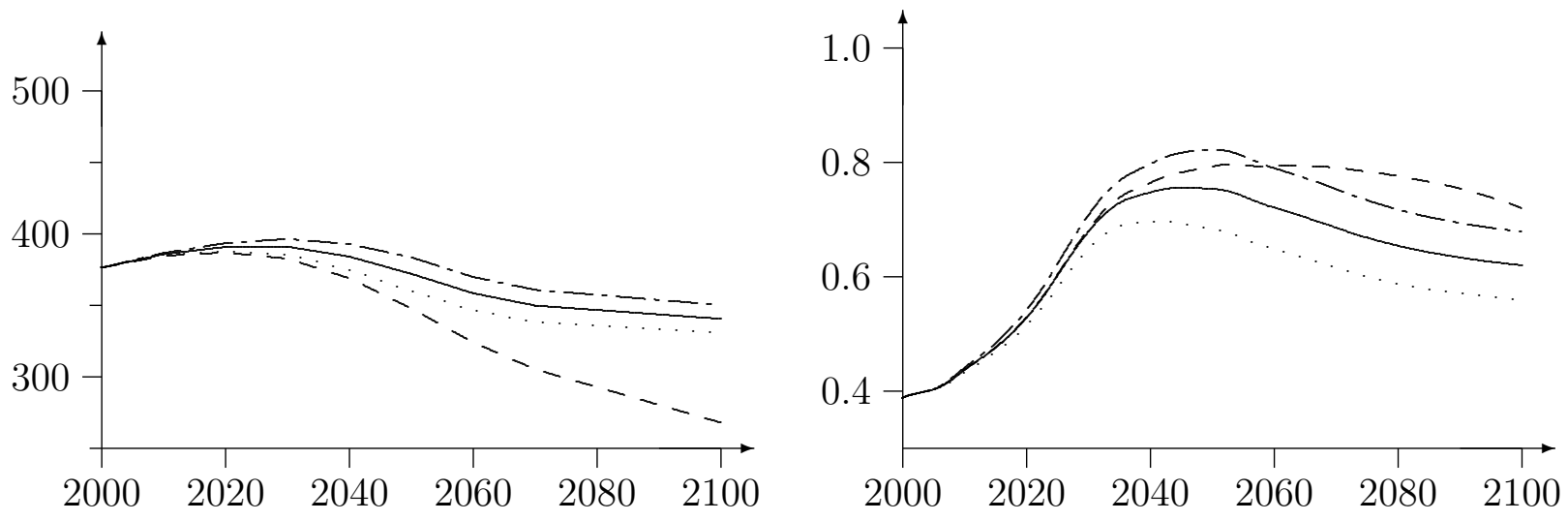

(c) Japan
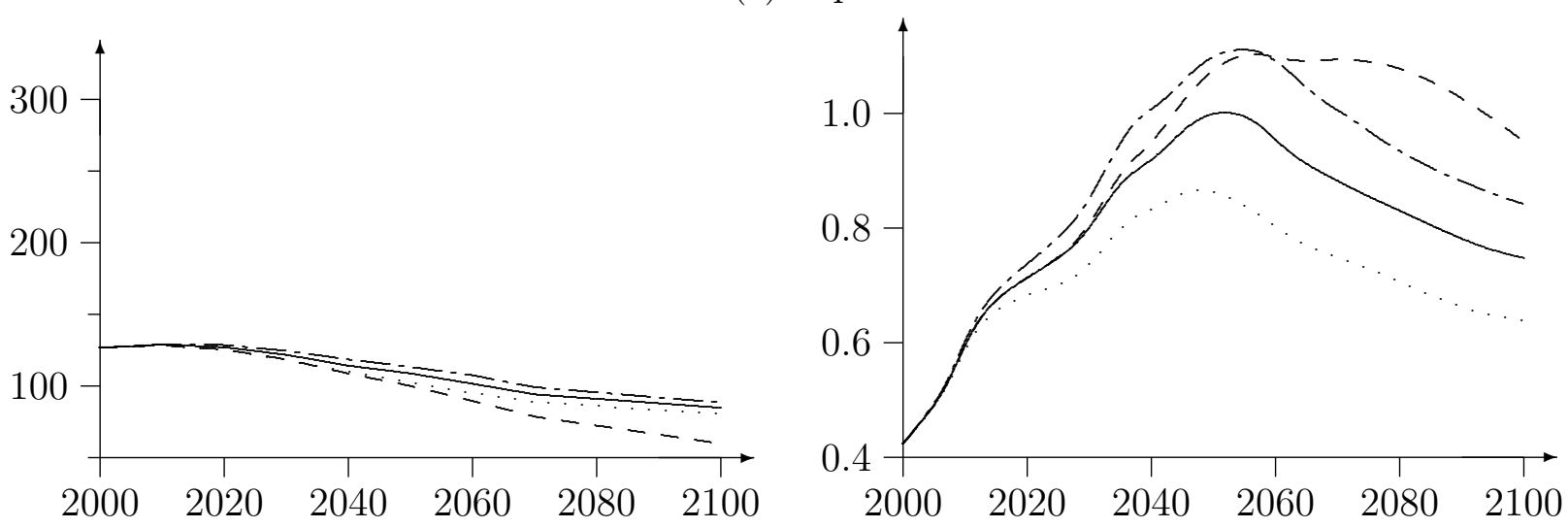

_ Base case - - - Constant fertility Constant mortality

-. - Lower mortality 
population will increase to 505 million by 2100. In contrast, keeping fertility rates constant through 2050 in the EU and Japan lowers their respective populations to 268 million and 60 million in 2100. Under these scenarios, dependency ratios would fall relative to the baseline in the U.S. and increase relative to the baseline in Europe and Japan. However, as shown in Figure 5 , it takes quite a while for changes in fertility rates to materially alter dependency ratios. In contrast to the effects of fixing fertility rates for a half century, fixing mortality rates at their current values reduces the future populations and the dependency ratios in all three regions. However, the effects are much smaller compared to those arising from stabilizing fertility rates. Of course, the opposite happens, if mortality is increased compared to the baseline scenario.

As already discussed above, the household composition changes when our population ages and these changes in the number of children affect individual consumption and saving decisions. Given age $a$ of an agent in income class $k$ in a specific year $t$, the number of her children is calculated as

$$
K I D(a, t, k)=\sum_{j=u}^{m} \frac{N(j, t, a-j, k)}{\sum_{s=23}^{45} N(a, t, s, k)} \quad 23 \leq a \leq 65, k=1,2,3,
$$

where $u=\max (0 ; a-45)$ and $m=\min (20, a-23)$. Recall that agents younger than 23 have no children and those over 65 have only adult children, i.e. $K I D(a, t, k)=0$ for $0 \leq a \leq 22$ and $66 \leq a \leq 90$. Agents in between these ages have children. Take, for example, a 30 year-old agent. Such an agent has children who were born in the years $(a-j)$ since she/he was 23 . In year $t$, these children are between age $0 \leq j \leq 7$. The KID-function (1) sums the total number of kids of the respective parent-income class generation and divides it by the total number of parents of age $a$ in year $t$ who belong to income class $k$. This function takes into account that the family's age structure will change over time due to changing fertility. This approach permits the distribution of births by the age of parents to change over time - an important improvement relative to the birthing process stipulated in Kotlikoff, et. al. (2001).

\section{The Household Sector}

As previously mentioned, we do not distinguish between natives and immigrants once the immigrants have joined the native earnings- and age-specific cohorts. The model's preference structure is represented by a time-separable, nested, CES utility function. Remaining lifetime utility $U(j, t, s, k)$ of a generation of age $j$ at time $t$ whose parents were age $s$ at time of birth and who belongs to income class $k$ takes the form

$$
U(j, t, s, k)=V(j, t, s, k)+H(j, t, s, k)
$$

where $V(j, t, s, k)$ records the agent's utility from her/his own goods and leisure consumption and $H(j, t, s, k)$ denotes the agent's utility from the consumption of her/his children. The two 
sub-utility functions are defined as follows:

$$
\begin{aligned}
V(j, t, s, k) & =\frac{1}{1-\frac{1}{\gamma}} \sum_{a=j}^{90}\left(\frac{1}{1+\theta}\right)^{a-j} P(a, i)\left[c(a, i, s, k)^{1-\frac{1}{\rho}}+\alpha \ell(a, i, s, k)^{1-\frac{1}{\rho}}\right]^{\frac{1-\frac{1}{\gamma}}{1-\frac{1}{\rho}}} \\
H(j, t, s, k) & =\frac{1}{1-\frac{1}{\gamma}} \sum_{a=j}^{90}\left(\frac{1}{1+\theta}\right)^{a-j} P(a, i) K I D(a, i, k) c_{K}(a, i, s, k)^{1-\frac{1}{\gamma}},
\end{aligned}
$$

where $c(a, i, s, k)$ and $\ell(a, i, s, k)$ denote consumption and leisure, respectively, and $i$ is defined as $i=t+a-j$. The children's consumption of income class $k$ parents who are age $a$ in period $i$ and whose parents were age $s$ at the time of their birth is defined as $c_{K}(a, i, s, k)$. Note that the number of children is independent of the grandparent's age at the time of the birth of the parents.

Since lifespan is uncertain, the utility of consumption in future periods is weighted by the survival probability of reaching age $a$ in year $i$

$$
P(a, i)=\prod_{u=j}^{a}[1-d(u, u-a+i)],
$$

which is determined by multiplying the conditional survival probabilities from year $t$ (when the agent's age is $j$ ) up to year $i$. Note that $d(j, t)$ is the mortality probability of an agent age $j$ in year $t$. The parameters $\theta, \rho, \alpha$ and $\gamma$ represent the "pure" rate of time preference, the intratemporal elasticity of substitution between consumption and leisure at each age $a$, the leisure preference parameter, and the intertemporal elasticity of substitution between consumption and leisure in different years, respectively.

Given the asset endowment a $(j, t, s, k)$ of the agent in year $t$, maximization of $(2)$ is subject to a lifetime budget constraint defined by the sequence:

$$
\begin{array}{r}
\mathrm{a}(j+1, t+1, s, k)=[\mathrm{a}(j, t, s, k)+I(j, t, s, k)](1+r(t))+w(t) E(a, k)[h(a, t)-\ell(a, t, s, k)] \\
-T(j, t, s, k)-c(j, t, s, k)-K I D(j, t, k) c_{K}(j, t, s, k),
\end{array}
$$

where $r(t)$ is the pre-tax return on savings and $I(j, t, s, k)$ denotes the inheritance the agent receives in year $t$. When the parents die between age 68 and 90 , their remaining assets are split between their children. Consequently, inheritances of agents who are age $j$ in year $t$ and whose parents were age $s$ at their birth are defined as follows:

$$
I(j, t, s, k)=\frac{d(j+s) \bar{A}(j+s, t, k)}{\sum_{u=23}^{45} N(j+s-u, t, u, k)} .
$$

The numerator defines the aggregate assets of income class $k$ parents who die in year $t$ at age $j+s$. The denominator defines these parents' total number of children who are between ages $j+s-45$ and $j+s-23$ in year $t$. The receipt of inheritances requires us to distinguish members of each cohort according to the ages of their parents at birth. The parents' ages at 
death determine when the children receive their inheritances. While the oldest children (born when their parents are age 23) receive their inheritances between ages 45 and 67 , the youngest children (born when their parents are age 45) receive their inheritances earlier in life, between ages 23 and 45 .

As in Altig et al. (2001) and Kotlikoff et al. (2001), we assume that technical progress causes the time endowment $h(\cdot)$ of each successive generation to grow at the rate $\lambda$, i.e.

$$
h(a, i)=(1+\lambda) h(a, i-1) .
$$

Gross labor income of the agent in year $t$ is derived as the product of her/his labor supply and her/his wage rate. The latter is the product of the gross wage rate $w(t)$ in period $t$ and the age- and class-specific earnings ability.

$$
\begin{array}{ll}
E(a, k)=\xi(k) e^{4.47+0.033(a-20)-0.00067(a-20)^{2}}(1+\lambda)^{a-21} & \text { with } \\
& \xi(1)=0.2, \xi(2)=1.0, \xi(3)=5.0
\end{array}
$$

The middle-income class profile is taken from Auerbach and Kotlikoff $(1987,52)$. The shift parameters $\xi(k)$ are then applied to derive income class-specific profiles. Moreover, since technological change is an important determinant of secular growth over the life cycle, we multiply the age-specific longitudinal earnings ability profile by the term involving $\lambda$. Hence, the longitudinal age-wage profile is steeper the greater is the rate of technological change.

The net taxes $T(j, t, s, k)$ of an agent in year $t$ consist of consumption, capital income, and progressive wage taxes as well as social security contributions net of pensions received. Due to our assumed ceiling on payroll tax contributions, pension, disability insurance and healthcare contribution rates differ across agents. Each agent's pension benefits depend on her/his pre-retirement earnings history, while health care and disability transfers are provided on a per capita basis to all eligible age groups.

Given individual consumption, leisure, and asset levels of all agents, we can compute the aggregate variables. For example, the aggregate value of assets $A(t+1)$ in period $t$ is computed from

$$
A(t+1)=\sum_{k=1}^{3} \sum_{a=21}^{90} \underbrace{\sum_{s=23}^{45} \mathrm{a}(a+1, t+1, s, k) N(a, t, s, k)}_{\bar{A}(a+1, t+1, k)}
$$

Since households die at the beginning of each period, we have to aggregate across all agents who lived in the previous period in order to compute $\bar{A}(a+1, t+1, k)$, which we need for the calculation of bequests, see (7). If we aggregate across agents who live in period $t+1$, i.e.,

$$
\mathcal{A}(t+1)=\sum_{k=1}^{3} \sum_{a=21}^{90} \sum_{s=23}^{45} \mathrm{a}(a, t+1, s, k) N(a, t+1, s, k)
$$

assets of the arriving immigrants of period $t+1$ are included. 
Finally, aggregate labor supply of agents in year $t, L(t)$, is computed from the individual labor supplies, i.e.

$$
L(t)=\sum_{k=1}^{3} \sum_{a=21}^{90} \sum_{s=23}^{45} E(a, k)[h(a, t)-\ell(a, t, s, k)] N(a, t, s, k) .
$$

\section{The Production Sector}

The economy is populated by a large number of identical firms, the total number of which is normalized to unity. Aggregate output (net of depreciation) is produced using Cobb-Douglas production technology, i.e.

$$
F(K(t), L(t))=\phi K(t)^{\varepsilon} L(t)^{1-\varepsilon}
$$

where $K(t)$ is aggregate capital in period $t, \varepsilon$ is capital's share in production, and $\phi$ is a technology parameter. Since we posit convex capital adjustment cost, the firms' marketable output in year $t, Y(t)$, is given by the difference between gross output and adjustment costs, i.e.

$$
Y(t)=F(K(t), L(t))-0.5 \psi \Delta K(t)^{2} / K(t)
$$

where $\Delta K(t)$ measures investment in year $t$. The term $\psi$ is the adjustment cost coefficient. Larger values of $\psi$ imply higher marginal costs of new capital goods for a given rate of investment. The installation technology is linear homogeneous and shows increasing marginal cost of investment (or, symmetrically, disinvestment): faster adjustment requires a greater than proportional rise in adjustment costs.

Corporate taxes, $T^{k}(t)$, are given by

$$
T^{k}(t)=\tau^{k}(t)[Y(t)-w(t) L(t)-\epsilon(t) \Delta K(t)]
$$

where $\tau^{k}(t)$ and $\epsilon(t)$ define the corporate tax rate and the immediate write-off share of investment expenditures, respectively. Since adjustment costs are fully and investment expenditures are partly deductible from the tax base, arbitrage between new and existing capital implies that the latter has a price per unit of

$$
q(t+1)=1-\epsilon(t) \tau^{k}(t)+\left[1-\tau^{k}(t)\right] \psi \Delta K(t) / K(t)
$$

Similarly, the arbitrage condition arising from profit maximization requires identical returns to financial and real investments:

$$
r(t) q(t)=\left[1-\tau^{k}(t)\right]\left\{F_{K(t)}+0.5 \psi(\Delta K(t) / K(t))^{2}\right\}+q(t+1)-q(t) .
$$

The left side gives the return on a financial investment of amount $q(t)$, while the return on one unit of real capital investment is the net return to capital (which includes the marginal product of capital $F_{K(t)}$ plus the reduction in marginal adjustment costs) and capital gains. 


\section{The Government Sector}

The consolidated government issues new debt $\Delta B(t)$ and collects corporate taxes and net-taxes from households in order to finance general government expenditures $G(t)$ as well as interest payments on its debt:

$$
\Delta B(t)+T^{k}(t)+\sum_{k=1}^{3} \sum_{a=21}^{90} \sum_{s=23}^{45} T(a, t, s, k) N(a, t, s, k)=G(t)+r(t) B(t) .
$$

With respect to public debt, we assume that the government maintains an exogenously fixed ratio of debt to output. The progressivity of the wage tax system is modeled as in Auerbach and Kotlikoff (1987). Specifically, marginal wage tax rates rise linearly with the tax base.

$P Y(t)$ defines the aggregate payroll tax base, which differs from total labor earnings due to the ceiling on taxable wages. This ceiling is fixed at 250 (200, 168) percent of average income in the U.S. (EU, Japan). Aggregate average social security payroll tax rates $\hat{\tau}^{p}, \hat{\tau}^{h}$ and $\hat{\tau}^{d}$ are computed each period from the relevant budget constraint for the program and region in question. For the U.S., we determine the separate values of payroll tax rates for the Social Security pension system, Medicare, and the Social Security disability insurance systems, i.e.

$$
\hat{\tau}^{p}(t) P Y(t)=P B(t) \quad \hat{\tau}^{h}(t) P Y(t)=H B(t) \quad \text { and } \quad \hat{\tau}^{d}(t) P Y(t)=D B(t)
$$

where $P B(t), H B(t)$ and $D B(t)$ are total outlays of the pension, health care, and disability systems, respectively. In the EU and Japan, disability insurance is part of their respective state pension systems. Hence, we do not calculate separate disability insurance payroll tax rates for those regions.

Due to contribution ceilings, individual pension and health insurance payroll tax rates can differ from the payroll tax rate. Above the contribution ceiling, marginal social security contributions are zero and average social security contributions fall with the agent's income. To accommodate this non-convexity of the budget constraint, we assume that the highest earnings class in each region pays pension and in the EU and Japan, health insurance payroll taxes, up to the relevant ceilings, but faces no pension and no health care payroll taxes at the margin. The other earnings classes are assumed to face the full statutory rate on all earnings. In the U.S., the disability payroll tax is modeled in an equivalent manner. However, since there is no ceiling on U.S. Medicare taxes, all earnings groups are assumed to face the health insurance payroll tax at the margin.

If a $k$-income class agent, whose parents were $s$ years old at his birth, retires in year $z$ at the exogenously set retirement age $\bar{a}(z)$, her/his pension benefits $\operatorname{Pen}(a, i, s, k)$ in years $i \geq z$ when he is age $a \geq \bar{a}(z)$ depend linearly on her/his average earnings during his working time $\bar{W}(z, s, k)$ :

$$
\operatorname{Pen}(a, i, s, k)=\omega_{0}+\omega_{1} \times \bar{W}(z, s, k) .
$$

The region-specific parameters $\omega_{0}, \omega_{1}$ were chosen in order to approximate the replacement rates relative to individual lifetime earnings as reported in Whitehouse (2002). 
General government expenditures $G(t)$ consist of government purchases of goods and services, including educational expenditures and health outlays. Over the transition, government purchases of goods and services are held fixed per capita with an adjustment for annual technological change. Age-specific education, health, and disability outlays are also held fixed over the transition with the same adjustment for technological change. The government's budget (18) is balanced each year by adjusting the intercept on our linear formula for the average wage tax rate.

\section{World Equilibrium}

Up to now we've described the model for the representative economy. The three regions of the model are connected through the world capital market. Consequently, the aggregate value of world assets equals the market value of the world-wide capital stock plus the value of all outstanding regional government bonds:

$$
\sum_{x \in W} \mathcal{A}(t, x)=\sum_{x \in W}[q(t, x) K(t, x)+B(t, x)], \quad \text { with } \quad W=\{U . S ., E U, \text { Japan }\} .
$$

\section{Solving the Model}

To solve the model we first need to specify the preference, technology, and policy parameters. Table 1 reports our main parameter values. The preference and technology parameters are mostly taken from Kotlikoff, et al. (2001). The reported debt levels in the U.S., Europe and Japan were chosen to match real interest payments reported in European Commission (2003) for the year 2000, while the retirement ages are taken from Bloendal and Scarpetta (1999) for the U.S. and the EU and from Whitehouse (2002) for Japan. The consumption tax rate for the U.S. is taken from Kotlikoff, et. al. (2001). For the EU, the consumption tax rate is the unweighted average of the indirect tax rates in the member states. In the case of Japan, the consumption tax rate is set to match the structure of tax revenues in year 2000. In addition, we specify the parameters of the progressive wage tax systems in each region in order to generate realistic average and marginal tax rates (reported below), while the proportional term is computed endogenously to balance the budget.

In calibrating our model, we use Japanese age-specific government health care expenditures profiles for Japan. In the case of the EU, we use the German profile. For the U.S., the Medicare program applies only to households older than 65. We assume uniform Medicare expenditures by age among those over age 65. We make the same uniform age-distribution assumption with respect to the U.S. disability insurance system, which we assume applies only to those older than 20 and younger than 65.

We use the German age-specific education profile for all regions in the model and rescale it to get realistic education outlays in year 2000 in each region (see below). In addition to these parameter values, our model requires an initial distribution of assets by age and income class for each region. These profiles are region-specific. ${ }^{4}$

\footnotetext{
${ }^{4}$ Data on Japanese asset profiles were provided by Charles Horioka, while the European profiles were adjusted from German data provided by Reinhold Schnabel. U.S. Data were derived from the 1998 Survey of Consumer Finances.
} 
Table 1: Parameter values of the Model

\begin{tabular}{|c|c|c|c|c|}
\hline & \multirow[t]{2}{*}{ Symbol } & \multicolumn{3}{|c|}{ Value } \\
\hline & & U.S. & $\mathrm{EU}$ & Japan \\
\hline \multicolumn{5}{|l|}{ Utility function } \\
\hline time preference rate & $\theta$ & & 0.02 & \\
\hline intertemporal elasticity of substitution & $\gamma$ & & 0.25 & \\
\hline intratemporal elasticity of substitution & $\rho$ & & 0.4 & \\
\hline leisure preference parameter & $\alpha$ & & 1.5 & \\
\hline \multicolumn{5}{|l|}{ Production function } \\
\hline technology level & $\phi$ & 1.041 & 1.048 & 1.049 \\
\hline capital share in production & $\varepsilon$ & & 0.25 & \\
\hline adjustment cost parameter & $\psi$ & & 10.0 & \\
\hline technical progress & $\lambda$ & & 0.01 & \\
\hline \multicolumn{5}{|l|}{ Policy parameters } \\
\hline consumption tax rate (in \%) & $\tau^{c}$ & 11.3 & 19.5 & 13.0 \\
\hline capital tax rate (in \%) & $\tau^{r}$ & 11.4 & 13.3 & 10.0 \\
\hline corporate tax rate (in \%) & $\tau^{k}$ & 10.0 & 13.3 & 15.0 \\
\hline expensing fraction (in \%) & $\epsilon$ & 20.0 & 20.0 & 30.0 \\
\hline debt (in \% of national income) & $B / Y$ & 40 & 50 & 48 \\
\hline age of retirement & & 63 & 60 & 60 \\
\hline capital share in the U.S. (in \%) & & 95.8 & 3.4 & 0.8 \\
\hline capital share in the EU (in \%) & & 2.0 & 97.8 & 0.2 \\
\hline capital share in Japan (in \%) & & 0.7 & 0.8 & 98.5 \\
\hline
\end{tabular}

To run our model as an open world economy, we also need to specify how aggregate world assets are distributed across regions. For each economy, we specify these distributions based on calculations reported in Kraay, et. al. (2000). Investment in all regions exhibits a strong home bias. To be precise, more than 90 percent of domestic assets are currently invested in the home region. The portfolio shares of the different regions and the capital stocks in each region in our initial year 2000 are used to compute aggregate national asset holdings. The initial developed world capital stock, the regional ratios of government debt to GDP, and the international, intergenerational, and intragenerational distributions of assets constitute the initial conditions needed to solve the model. Given these data, our model applies a Gauss-Seidel algorithm to solve for the perfect foresight general equilibrium transition path of the economy. Our algorithm starts with initial guesses for capital stocks and labor supplies in each region for the remaining years of the transition. Next we compute from equation (16) the path of region-specific market prices of capital. The path for the world interest rate after 2000 is derived from the arbitrage condition (17) for the U.S. This condition (17) is also used to update values of the existing capital stock in year 2000 in each region. Next, regional wage rates are computed by setting them equal to their respective marginal products of labor. From the capital market equilibrium 
condition (21) we derive the values of the national capital stock and government debt. These aggregate values are next distributed to the savers of the different regions based on the current portfolio shares. Next we update the initial age-specific asset holdings in year 2000 for each region in order to match the computed aggregate national savings. Given the initial individual assets, the time path of tax rates (which are based on guesses in the first iteration) and factor prices, household decisions on consumption and labor supply are computed and aggregated. Then we update the path for wage tax rates, the social security payroll tax rate, and debt given the government budget constraints (18) and (19). Finally, we compute new paths for the capital stocks in each region using the capital market equilibrium condition (21) as well as (16). The new values for capital and labor are then weighted with the initial guesses of these supplies to form guesses of the time paths of these variables. The algorithm then iterates until the paths of capital stock and labor converge to a fixed point. We give our economy 300 years to reach to a steady state. In fact, our model reaches a steady state to many decimal places prior to year 300. It also converges very tightly around the equilibrium transition path.

\section{Initial Equilibrium and the World Economy's Baseline Transition Path}

Table 2 reports key macroeconomic variables in 2000 in the three regions. Note that there is a fairly close accordance between actual and computed national income account measures of private consumption and government purchases. The one exception is Japanese government purchases. The official data seem too high given the reported ratio of tax revenues to national income. In our calibration, we chose to benchmark government purchases based on the ratio of tax revenues to national income.

The reported shares in education, pensions and health are very close to actual levels ${ }^{5}$. The same applies to the social security payroll tax rates and the level and progressivity of the three income taxes. Concerning the overall structure of tax revenues, the assumed tax rates on capital income, corporate income and consumption as well as the expensing fractions (see Table 1) yield a realistic pattern ${ }^{6}$. Finally, the model's year-2000 capital-output ratios seem reasonable not only relative to U.S. Commerce Department figures, but also in terms of the year-2000 interest rate, which equals 8.1 percent. As discussed in Fehr, Jokisch and Kotlikoff (2004b), calibrating the model to a lower initial capital-output ratio will alter the extent to which simulated capital-labor ratios decline and real wages fall over the developed world's transition path.

Now we turn to the simulation results for the baseline transition where, to repeat, we incorporate the medium variant of the United Nations population projections. The transition paths for the three regions are reported in the upper panels of Tables 3 to 5 for the U.S., EU and Japan.

Although the economies are aging, the baseline path shows a steadily increase in effective labor supply in all three regions. This may seem surprising especially for Japan and the EU where the population and work force decline over time (see Figure 4). The explanation lies in our assumed rate of labor-augmenting technological change permitting greater effective labor

\footnotetext{
${ }^{5}$ See European Commission (2003), Dang et al. (2001, 26), IPSS (2003, 3) and OECD (2002, 178 and 2003).

${ }^{6}$ Actual values are calculated from European Commission (2003) and Joumard (2001).
} 
Table 2: The year 2000 of the baseline path*

\begin{tabular}{|c|c|c|c|c|c|c|}
\hline & \multicolumn{3}{|c|}{ Model } & \multicolumn{3}{|c|}{ Official** } \\
\hline & U.S. & $\mathrm{EU}$ & Japan & U.S. & $\mathrm{EU}$ & Japan \\
\hline \multicolumn{7}{|l|}{ National Income } \\
\hline private consumption & 78.2 & 70.3 & 73.1 & 77.6 & 67.8 & 67.8 \\
\hline government purchases of goods and services & 22.9 & 32.6 & 22.3 & 23.0 & 32.1 & 33.4 \\
\hline current account & -1.3 & -0.8 & 5.2 & -4.6 & -0.4 & 3.0 \\
\hline \multicolumn{7}{|l|}{ Government indicators } \\
\hline aggregate education outlays & 5.9 & 6.0 & 4.2 & 5.9 & 6.0 & 4.3 \\
\hline aggregate pension benefits & 6.2 & 11.5 & 10.8 & 5.7 & 11.6 & 10.8 \\
\hline aggregate health benefits & 2.2 & 6.3 & 5.2 & 2.5 & 6.2 & 6.8 \\
\hline aggregate disability benefits & 1.3 & - & - & 0.9 & - & - \\
\hline pension contribution rate (in \%) & 8.9 & 17.1 & 16.7 & 10.6 & - & 17.3 \\
\hline health care contribution rate (in \%) & 2.9 & 9.4 & 8.0 & 2.9 & - & 8.0 \\
\hline disability insurance contribution rate (in \%) & 1.9 & - & - & 1.9 & - & - \\
\hline Tax revenues & 21.9 & 29.8 & 20.7 & 26.6 & 32.5 & 20.7 \\
\hline direct taxes & 13.1 & 16.1 & 11.2 & 17.9 & 16.5 & 10.5 \\
\hline personal income taxes & 10.6 & 12.7 & 7.4 & 14.7 & 12.8 & 6.2 \\
\hline wage taxes & 7.4 & 9.0 & 4.9 & - & - & - \\
\hline capital taxes & 3.2 & 3.7 & 2.5 & - & - & - \\
\hline corporate income taxes & 2.5 & 3.4 & 3.8 & 3.2 & 3.7 & 4.3 \\
\hline indirect taxes & 8.8 & 13.7 & 9.5 & 8.7 & 16.0 & 10.2 \\
\hline \multicolumn{7}{|l|}{ Wage tax rates (in \%) } \\
\hline average & 10.2 & 12.1 & 6.6 & - & - & - \\
\hline marginal & 17.2 & 18.2 & 12.1 & - & - & - \\
\hline capital output ratio & 3.2 & 3.2 & 2.8 & - & - & - \\
\hline interest rate (in \%) & & 8.1 & & - & - & - \\
\hline
\end{tabular}

$*$ in percent of national income if not stated different

** European Commission (2003) 
supply by each successive cohort. Thus, the future decrease in the labor force is offset in the EU and Japan and the growth in the actual number of workers in the U.S. is augmented. However, effective labor supply grows at much different rates in the three regions. In Japan it increases by 63 percent over the century. In the EU it more than doubles over the same period. And in the U.S. it increases over the century by a factor of four. The differences in effective labor supply growth across the three regions materially affect overall economic growth. In the U.S. output grows by a factor of 3.6 over the next 100 years. It grows by a factor of 2.2 in the EU and 1.4 in Japan.

A second key feature of our base-case simulation is the emergence over time of a significant capital shortage. Although the overall capital stock doubles in the U.S. over the century, capital per unit of human capital declines. This development is even more dramatic in the EU and Japan where the capital stocks fall during the transition. The observed capital shortages lower real wages per unit of human capital by 16 percent in Japan and by almost 20 percent in the U.S. and the EU over the course of the century. The associated increase in the real interest rate over this period is 390 basis points. This major crowding out of capital can be explained by the increases in the payroll and wage tax rates, which are reported in the last two columns of the charts. Over the century, combined social security payroll tax and wage tax rates rise by 77 percent in the U.S., by 64 percent in the EU, and by 79 percent in Japan. By 2100, the combined payroll plus average wage tax rate equals 42.4 percent in the U.S., 63.5 percent in the EU, and 56.2 percent in Japan. These very high rates of taxation reduce the ability of workers to save and, therefore, accumulate claims to physical capital.

The Tables also show that the different timing of the aging process in the three regions induces major capital flows. Since aging is much more severe in Europe and Japan, the U.S. experiences capital inflows from these regions throughout the century. Consequently, the initial U.S. current account deficit of 1.3 percent of national income improves rather slowly and finally turns into a surplus in the second half of the century. The opposite happens in the capitalexporting countries. In the EU, the initial current account deficit improves but returns to a deficit again after 2040. In Japan the initial current account surplus of 5.2 percent declines steadily until the aging process peaks in the second half of the century.

Despite the aging process, asset prices increase in the U.S. and in Europe, but they fall temporarily in Japan below their initial values. The latter outcome supports the widely held belief that aging will lower worldwide capital prices as the growing number of elderly start to sell their assets. Our simulations suggest that this effect will only be significant in Japan, although asset prices are also dampened in the other countries.

The final columns report the development of bequests (relative to national income (NI)) during the transition. While many people believe that bequests will rise significantly during the aging process, our results belie this view. This perhaps surprising result is mainly due to the increase in life expectancy during the transition. Reductions in mortality rates reduce the levels of unintended bequests left to children. 


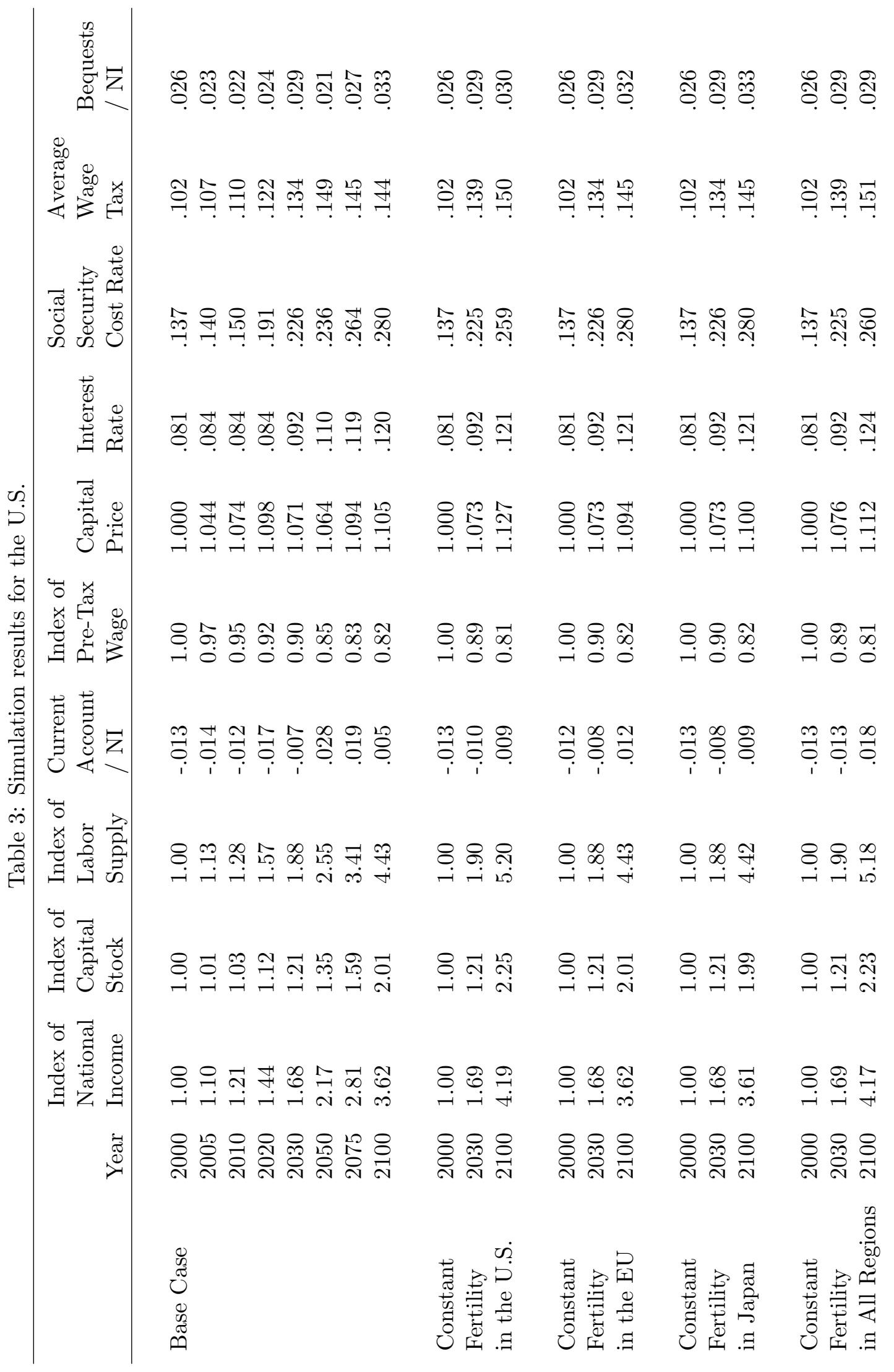




\begin{tabular}{|c|c|c|c|c|}
\hline & 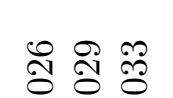 & 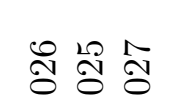 & $\ddot{d}$ & ֻั \\
\hline 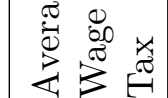 & 实苜孚 & 欲密 & 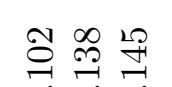 & 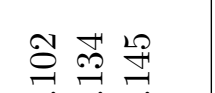 \\
\hline 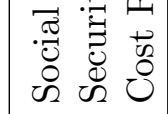 & 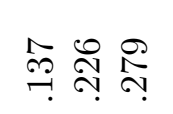 & & & 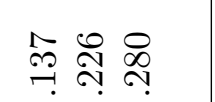 \\
\hline & 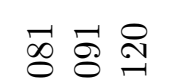 & 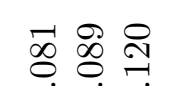 & 용 용 웍 & $\vec{\infty} \vec{\delta} \vec{\delta} \vec{I}$ \\
\hline & 容芯芯苛 & 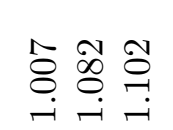 & 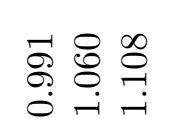 & 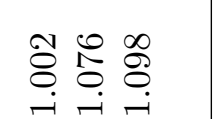 \\
\hline 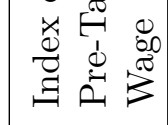 & 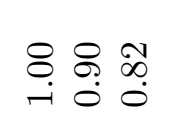 & 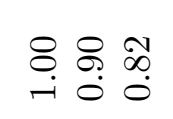 & 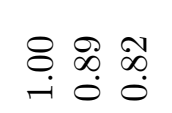 & 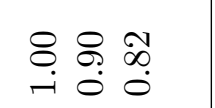 \\
\hline 吾 & 骂 & $\stackrel{0}{0}$ & 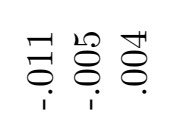 & \\
\hline 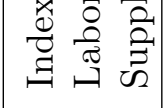 & 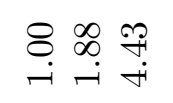 & 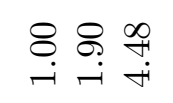 & 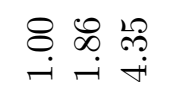 & 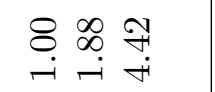 \\
\hline 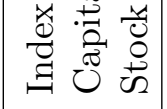 & 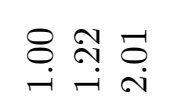 & 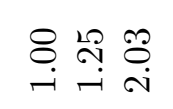 & $\underset{\sim}{8} \stackrel{8}{8} \stackrel{8}{\leftrightarrow}$ & $\stackrel{8}{\stackrel{8}{-}}$ \\
\hline & 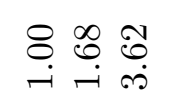 & $\underset{ن}{8}$ & 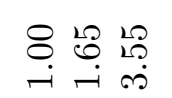 & \\
\hline 莡 & ڤ్రి & ڤ్రి & ڤ్రి & ఏ \\
\hline & 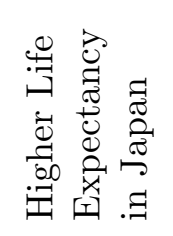 & 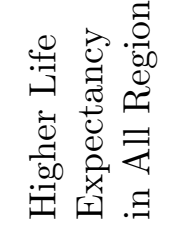 & 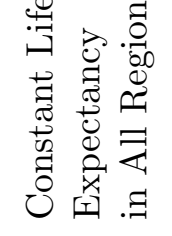 & \\
\hline
\end{tabular}




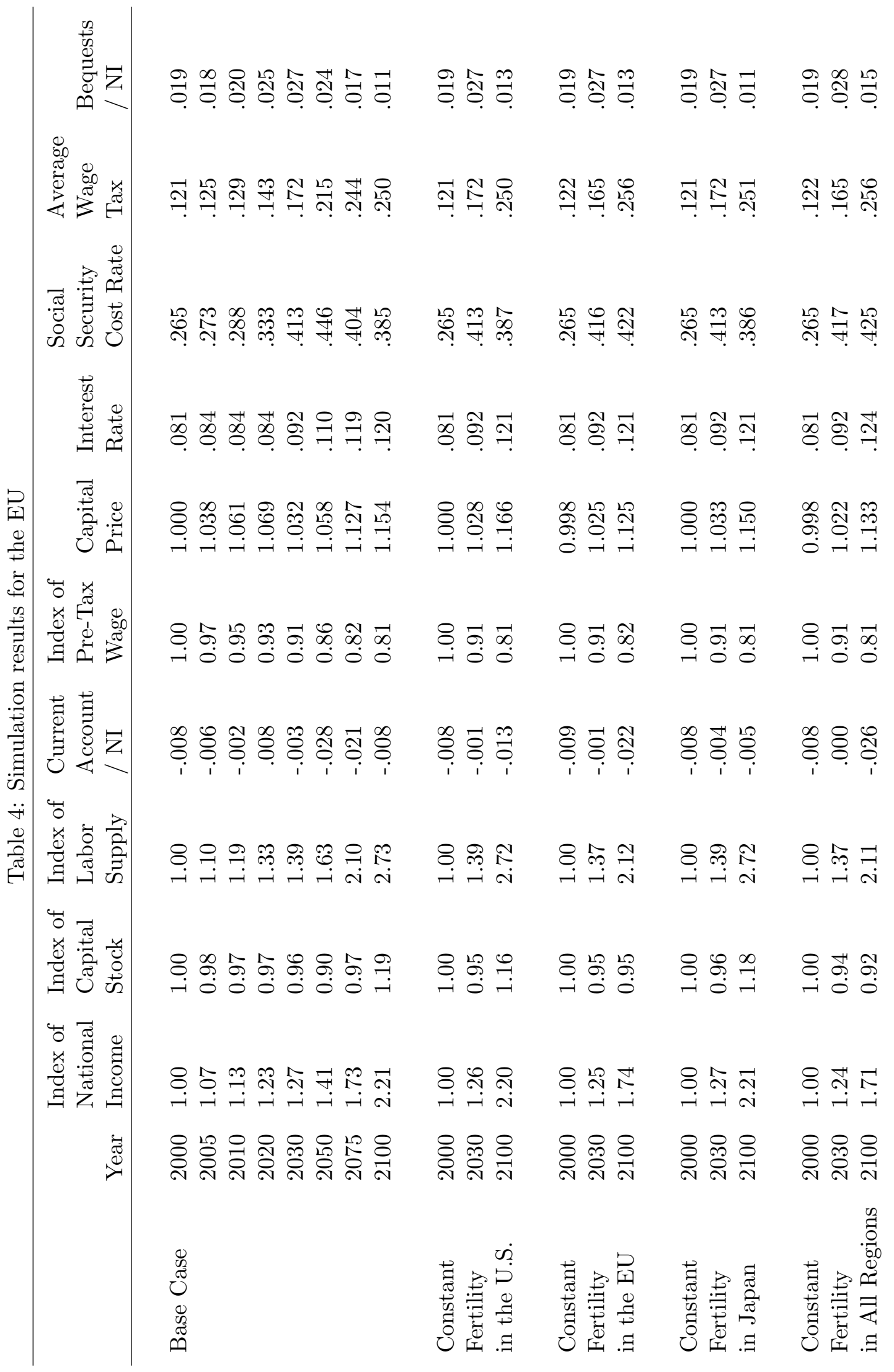




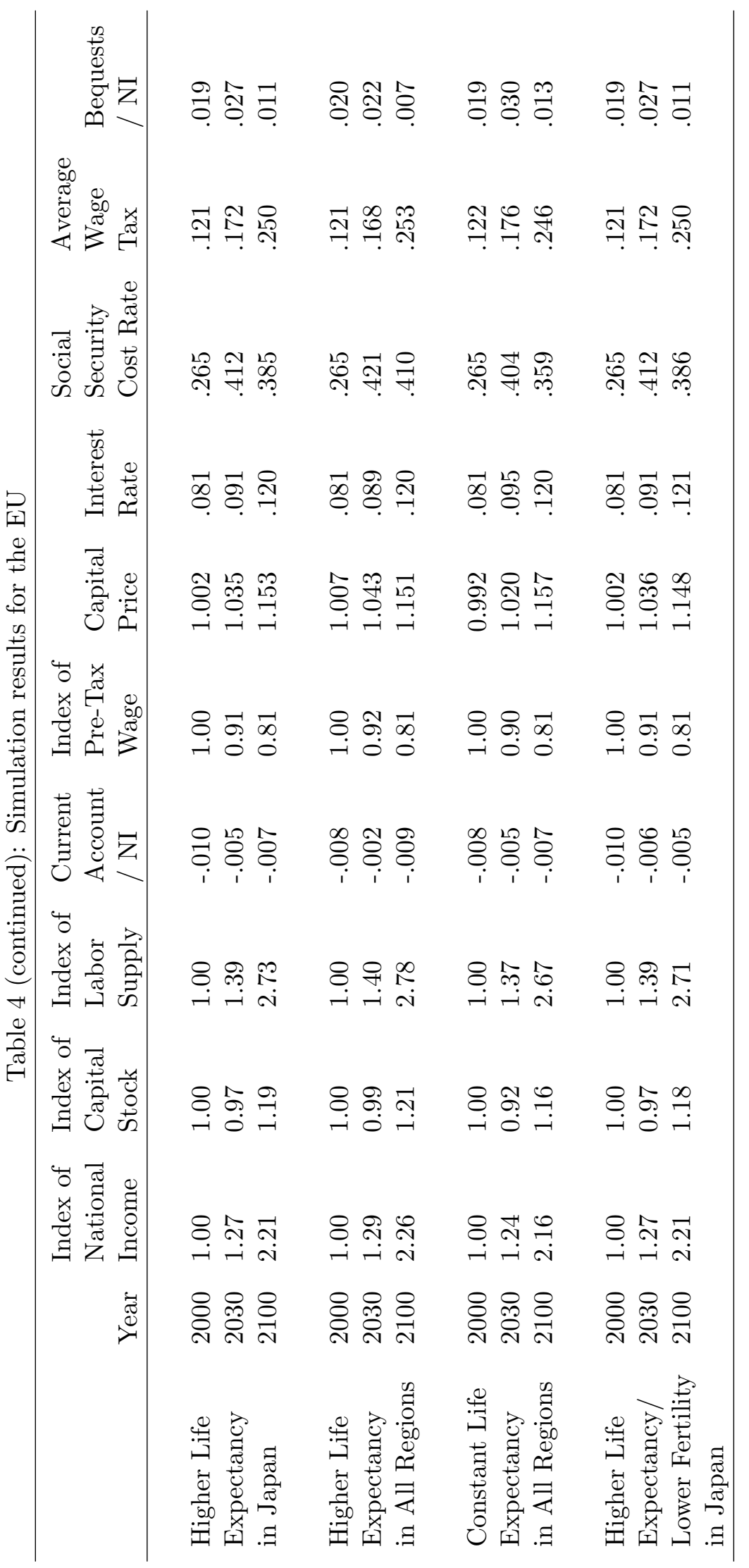




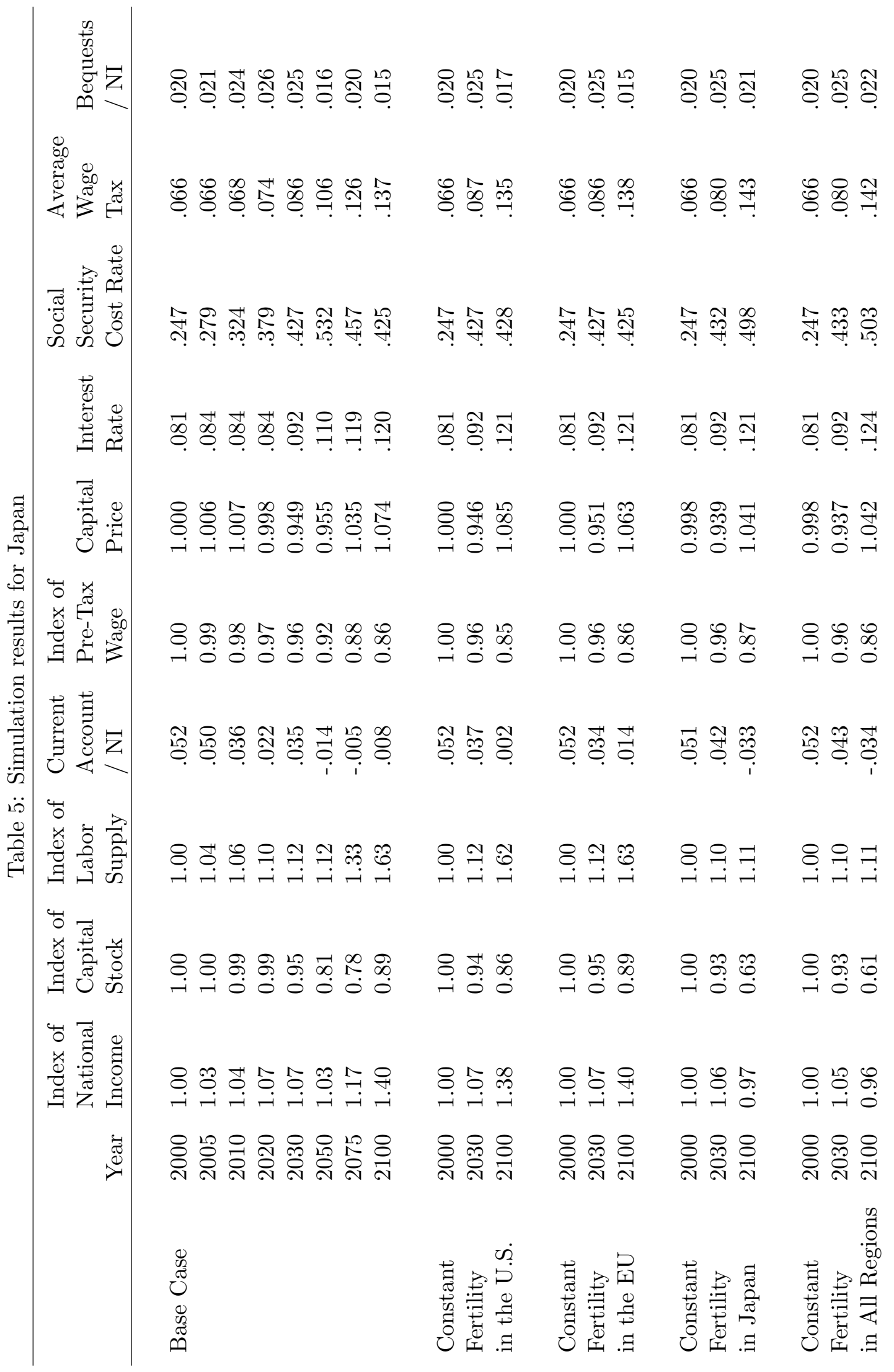




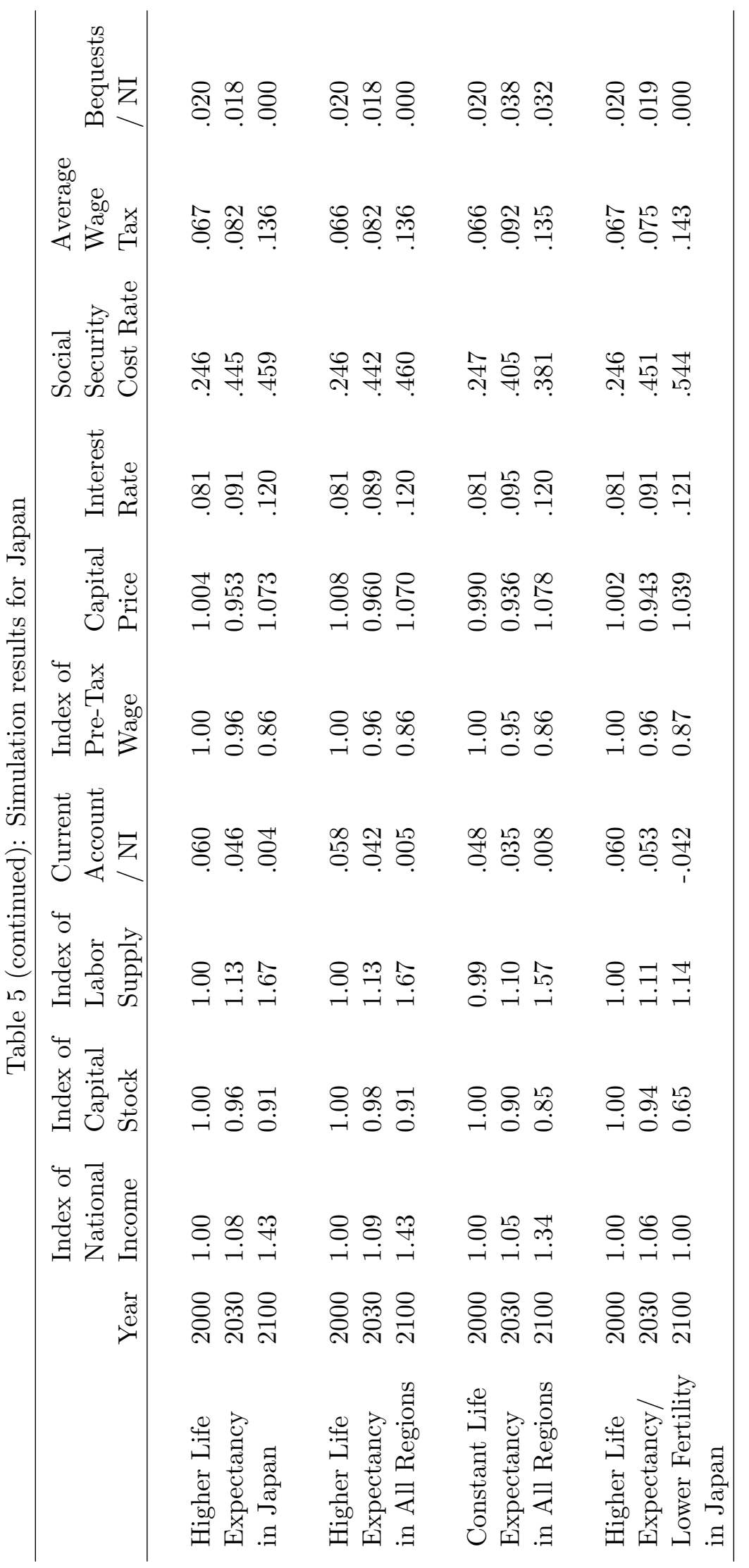




\section{The Impact of Fertility Changes}

This section considers what happens if fertility rates remain at their current levels through 2050. Since in the baseline path fertility rates fall in the U.S. and increase in the EU and in Japan, constant birth rates imply (compared to the baseline path) lower population growth in the EU and in Japan and higher population growth in the U.S. compared with the baseline paths (see Figures 4 and 5). In order to distinguish the different effects at work we analyze three isolated changes in fertility (compared to the baseline) in each region as well as a fourth scenario in which birth rates change in the U.S., the EU, and Japan simultaneously.

\section{Higher Fertility in the U.S.}

The second panels in Tables 3 through 5 show the impacts of keeping the initial fertility rate of 2.11 births per woman in the U.S. fixed through $2050^{7}$. In this simulation EU and Japanese birth rates follow the same paths as shown in Figure 3.

The higher short-term U.S. fertility rate increases that country's total population as well as its effective labor supply. The latter variable is first affected in 2022 when the first cohort generated by the higher birth rate enters the labor force. Effective labor supply in 2100 is raised by 17 percent and national income by 16 percent relative to the baseline simulation.

Due to the younger population age-structure and the increased labor supply, social security contribution rates in the U.S. decrease. In 2100 the social security payroll tax is 25.9 percent, compared to 28 percent in the base case. However, the average wage tax rate rises. Compared with the base case results, the average wage tax rate is 1.2 percentage points higher in 2075 and 0.6 percentage points higher in 2100 . This reflects the need to finance additional government expenditures associated with the population increase. Due to these opposite effects on after-tax wage income, the capital stock in 2100 is only 12 percent higher relative to the base case leading to a further decline in the capital-labor ratio. Hence, the pre-tax wage in the medium and long run is somewhat lower than in the base case and asset prices and the interest rate are slightly increased. Note also that bequests are slightly lower in the long run. This appears due to the fact that agents save less for their old age when they have more children.

There is very little impact on the EU and Japanese economies of maintaining high fertility in the U.S. through 2050. The U.S. attracts capital from the other two areas thanks to its more rapid growth in effective labor supply. Consequently, in the medium run the current accounts in the EU and Japan show increased capital exports compared to the baseline transition. These larger capital exports from the EU and Japan lead to small reductions in the levels of EU and Japanese national income. This explains why the social security payroll taxes in the EU and Japan rise somewhat between 2050 and 2100 relative to their base-case transition values.

\footnotetext{
${ }^{7}$ After 2050 fertility rates gradually decline again to their long run value of 1.8 in order to achieve a zero long-run population growth rate.
} 


\section{Lower Fertility in the EU and Japan}

The next two simulations, reported in the third and fourth panels of Tables 3-5, respectively, assume that fertility in the EU and Japan remains at their current levels of 1.46 and 1.28 births per woman through 2050. Again, after 2050, birth rates rise to achieve long-run zero population growth ${ }^{8}$.

The lower short-run fertility rates lead to smaller work forces and total populations in the EU and in Japan. In the EU, for example, labor supply in 2100 is 22 percent smaller and national income 21 percent smaller compared to the baseline values. These are big differences. In Japan, the maintenance of current fertility patterns through 2050 reduces effective labor supply at the end of the century by 32 percent and national income by over 40 percent. Indeed, the absolute size of the Japanese economy (as measured by national income) is smaller in 2100 than in 2000 notwithstanding 100 years of technological progress!

As Figures 4 and 5 show, dependency ratios in both regions rise compared to the baseline path. This necessitates larger increases in social security tax rates. On the other hand, average wage tax rates are slightly reduced during the early stages of the transitions since government expenditures decrease with the reduction in the sizes of the overall populations. After 2075, however, the reduction in the effective labor supply outweighs this factor and wage tax rates rise relative to the baseline paths. Consequently, households save less and export more capital to the U.S. Asset prices and the capital stock in both regions decline sharply compared to the base case. The somewhat higher capital-labor ratios during the transition increase pre-tax wages slightly.

Finally, note that the constant fertility rate simulations for Europe and Japan generate rather small spillover effects for the other two economies whose fertility rates evolve according to the base-case assumptions.

\section{Constant Fertility in All Regions}

Our final fertility simulation maintains constant fertility rates for 50 years in all three regions. In this simulation, opposite effects are at work. While the population in the U.S. is younger than in the base case, the European and Japanese economies are confronting a more severe aging process. Nevertheless, the resulting effects (see the fifth panels of Tables 3-5) are very much the same as in the scenarios with the isolated fertility changes.

\section{The Impact of Changes in Life Expectancy}

This section analyzes the economic effects of changing life expectancy in our model. As discussed in the introduction, no one knows whether longevity will continue to grow or reach a limit. Since the baseline path takes a median view with slowly decreasing mortality rates, the present section considers two extreme alternatives: a much sharper increase in life expectancy and a scenario in which mortality rates remain at their current levels. Japan offers an interesting special case since some projections assume a rise in longevity beyond 90 years, see Oeppen and

\footnotetext{
${ }^{8}$ In the EU this means a gradual increase in the fertility rate to 1.77 births per woman and in Japan a rise to 1.86 births per woman.
} 
Vaupel (2002). In our model this means that life span uncertainty completely vanishes as well as unintended bequests. Therefore, we first consider a scenario, where life expectancy in Japan increases to 91 years between 2000 and 2050 and remains at 91 thereafter, with no probability of dying prior to age 91. Next we increase life expectancy in all three regions through 2050 and keep it constant afterwards. The third simulation is inspired by Yakita (2001) who claims that an increase in life expectancy will lower fertility rates in Japan. Consequently we consider both a rise in life expectancy in Japan as well as the maintenance in Japan for the next half century of its current very low fertility rate.

\section{Higher Life Expectancy in Japan}

The simulation shown in the sixth panels of Tables 3-5 assumes that life expectancy at birth rises in Japan to age 91 by 2050 and remains constant thereafter. Life expectancy in the U.S. and EU follows the baseline path.

Higher life expectancy in Japan is expected to increase savings since agents need to finance longer retirements. However, the results in Table 5 show only a slight increase in the capital stock compared to the base case. The explanation here is twofold. First, rising longevity leads to a further increase in the dependency ratio compared to the base case (see Figure 5). Hence, the contribution rates to the pay-as-you-go financed social security systems rise to a larger extent during the transition so that in 2100 the payroll tax rates are 3.4 percentage points higher. This development discourages saving. Second, since in our model life span uncertainty gradually falls as life expectancy rises, bequests gradually decline until 2050 and are zero afterwards. Since now the agents consume all their resources in old age by themselves, savings implicitly fall compared to the baseline path ${ }^{9}$.

The spill over effects on the U.S. and the EU of the rise in the Japanese life expectancy are small. There are only slight increases in the capital stocks during the transition which is due to higher capital imports from Japan. Hence, the current account balances in both regions deteriorate.

\section{Higher Life Expectancy in All Regions}

In this section, we consider a simultaneous rise in longevity in all three regions. To be precise, life expectancy increases to 85 years in the U.S. and 86.9 years in the EU until 2050 compared to 83.8 years and 84.6 years, respectively, in the baseline transition path. These values find support by the projections of Tuljapurkar et al. (2000). For Japan we assume the same rise in longevity to 91 years as in the scenario above.

As already mentioned above, greater longevity raises the need for more resources after retirement. Therefore, the labor supply and the capital stock are raised in all three regions compared to the base case. The broadening of the tax base implies a slight decline in wage tax rates. However, at the same time, higher life expectancy leads to a rise in the dependency ratios to a much larger extent relative to the baseline transition path (see Figure 5). Hence, the social security contribution rates are increased by 1.2 percentage points in the U.S., 2.5

\footnotetext{
${ }^{9} \mathrm{~A}$ similar effect of increased longevity on altruistic bequests is discussed in Skinner (1985).
} 
percentage points in the EU, and 3.5 percentage points in Japan by 2100. This development hinders greater capital accumulation so that the increase in the capital stock is lower than in labor supply. Since agents now consume a bigger part of their resources by themselves, bequests are lower than in the base case.

While the current account in the EU is hardly affected by this scenario, the current accounts in the U.S. and Japan change markedly. Since the aging process in the U.S. still is less severe, more capital is imported from Japan during the first 30 years of the transition. Afterwards, this effect is reversed. Due to the overall capital scarcity, capital prices in all three regions during the first decades of the transition are higher compared to the base case.

\section{Constant Life Expectancy in All Regions}

Now we turn to a scenario where we keep the mortality in all three regions simultaneously constant. Hence, the life expectancy in the U.S. is 81.7 years, in the EU 82.2 years and in Japan 83.8 years during the whole transition path. As a consequence population aging is less severe in all three regions at the same time. However, Japan still faces the most severe aging process due to its lower fertility rates and its higher level of longevity compared to the other two regions. Nevertheless, the effects in Japan are most pronounced since in the base case the life span increases the most. For the simulation results see the eighth panels of Tables 3-5.

Due to the smaller number of elderly, social security payroll taxes at the peak of the aging process in 2050 are 2.8 percentage points in the EU, 5 percentage points in Japan and 1.4 percentage points in the U.S. below the corresponding values in the base case. Of course, this difference stems from the more significant rise in longevity in Japan during the baseline transition. The capital stock, the effective labor supply, and national income is lower in all three regions compared to the base case. The bequest-output ratio increases in all regions. In Japan it even more than doubles in the medium and long run showing the strong dissaving of the elderly in the baseline path.

Interestingly, the short-run current account deficit in the U.S. and the surplus in Japan are lower than in the base case. This shows that more capital from the U.S. is invested in Japan. In the medium and long run, more capital flows from the EU to the U.S. while the current account in Japan is much the same as in the baseline path. Since people save less, the initial capital prices are reduced in all regions. However, in the long run the lower capital stocks push up capital prices.

\section{Higher Life Expectancy and Lower Fertility in Japan}

Finally, we consider a scenario where we combine higher longevity and lower fertility in Japan as inspired by Yakita (2001). In this "worst case"' scenario life expectancy rises again to 91 years while at the same time fertility is fixed at the initial value of 1.28 births per woman until 2050. For the U.S. and the EU, the demographic process follows the path as assumed in the base case. The simulation results are reported in the ninth panels of Tables 3-5.

The changes in the macroeconomic variables in Japan are mostly an addition of the isolated effects. As a consequence, the increase in the social security tax rates are dramatic 
now. For example, in 2050 the payroll tax rate is 61.6 percent. The payroll and wage tax rate combined amount to even 70 percent while at the same time wages fall during the transition! This puts an enormous burden on the households and reduces the incentives to supply labor. In addition, capital accumulation drops sharply compared to the baseline path which is mainly due to the reduction in fertility.

Again, spillover effects on the U.S. and EU economy are almost negligible. The first part of the transition shows higher capital flows from Japan to the other two economies compared to the base case. This effect is reversed in the long run.

\section{Conclusion}

This paper applies the three-region dynamic general equilibrium life-cycle model introduced by Fehr, Jokisch and Kotlikoff $(2004 \mathrm{a}$, b) in order to analyze the economic effects of changes in fertility and mortality. The original model was modified in several ways. The new model includes realistic exogenous portfolio shares for international investment, an improved Japanese tax structure, corporate taxes and an updated population projection based on the medium variant of the UNPD (2003). Despite these adjustments, our baseline transition path highlights the same quantitative implications as in our previous papers. Population aging leads to a major capital shortage during the century due to dramatically increasing payroll and wage tax rates. This is accompanied by a decline in wages of almost 20 percent and an increase in the interest rate by 390 basis points.

Due to the strong home biases of investment flows, the immediate spillover effects of economic shocks are now small compared to our previous work. Firstly, we consider the economic impact of alternative fertility trends in the U.S., EU and Japan. Our findings suggest that in contrast to the public opinion - higher fertility cannot alleviate the demographic stresses. Although a higher number of births reduces social security contribution rates in the long run, it increases general government expenditures for education, etc. in the short and medium runs which offsets the positive effect of reduced payroll tax rates.

With respect to future trends in life expectancy, our simulations suggest that further increases in longevity have only a modest positive impact on saving rates. Although lower mortality increases the demand for resources during retirement, it also implies a further increase in the future payroll tax rates and a decline in unintended bequests, which both tend to reduce individual and aggregate savings. Due to these counterbalancing effects, capital accumulation is only modestly affected by changes in life expectancy, and the general economic impact of mortality trends is much smaller than the impact of fertility trends.

Our bottom lines are a) that there is little reason to expect future changes in fertility and/or mortality to alleviate the future demographic stresses facing the developed world and b) the only way to improve future economic conditions in the developed world is to engage in major and immediate fiscal adjustments. 


\section{References}

Altig, D., A.J. Auerbach, L.J. Kotlikoff, K.A. Smetters and J. Walliser (2001): Simulating Fundamental Tax Reform in the United States, American Economic Review 91, 574-595.

Auerbach, A.J. and L.J. Kotlikoff (1987): Dynamic Fiscal Policy, Cambridge.

Berkel, B., A. Börsch-Supan, A. Ludwig and J. Winter (2004): Sind die Probleme der Bevölkerungsalterung durch eine höhere Geburtenrate lösbar?, Perspektiven der Wirtschaftspolitik 5(1), 71-90.

Bloendal, S. and S. Scarpetta (1999): The Retirement Decision in OECD Countries, OECD Economics Department Working Paper 202, Paris.

Bloom, D.E., D. Canning and B. Graham (2003): Longevity and Life-cycle Savings, Scandinavian Journal of Economics 105, 319-338.

Cutler, D.M., J.M. Poterba, L.M. Sheiner and L.H. Summers (1990): An Ageing Society: Opportunity or Challenge? Brookings Papers on Economic Activity 1, 1-73.

Dang, T.T., P. Antolin and H. Oxley (2001); Fiscal Implications of Ageing: Projections of Age-related Spending, Economics Department Working Paper No. 305, OECD, Paris.

European Commission (2003): Statistical Annex to European Economy No. 4, Brussels.

Fehr, H., G. Halder, S. Jokisch and L.J. Kotlikoff (2003): A Simulation Model for the Demographic Transition in the OECD - Data Requirements, Model Structure and Calibration, Wuerzburg Economic Papers No. 45, University of Wuerzburg.

Fehr, H., S. Jokisch and L.J. Kotlikoff (2004a): The Developed World's Demographic Transition - The Roles of Capital Flows, Immigration, and Policy, forthcoming in: R. Brooks and A. Razin (eds.): The Politics and Finance of Social Security Reform, Cambridge University Press.

Fehr, H., S. Jokisch and L.J. Kotlikoff (2004b): The Role of Immigration in Dealing with Developed World's Demographic Transition, forthcoming in: FinanzArchiv.

Gokhale, J. L.J. Kotlikoff, J. Sefton and M. Weale (2001): Simulating the Transmission of Wealth Inequality via Bequests, Journal of Public Economics 79, 93-128.

Guest, R.S. and I.M. McDonald (2002): Would a Decrease in Fertility Be a Threat to Living Standards in Australia? The Australian Economic Review 35, 29-44.

Heijdra, B.J. and J.E. Ligthart (2004): The Macroeconomic Dynamics of Demographic Shocks, Paper presented at the 60th Congress of the IIPF.

Institute of Population and Social Security Research (IPSS) (2003): The Cost of Social Security in Japan, Statistical Report No. 13, Tokyo. 
Joumard, I. (2001): Tax systems in European Union countries, Economics Department Working Paper No. 301, OECD, Paris.

Kotlikoff, L.J., K.A. Smetters and J. Walliser (2001): Finding a Way out of America's Demographic Dilemma, NBER Working Paper No. 8258, Cambridge.

Kraay, A., N. Loayza, L. Serven and J. Ventura (2000): Country Portfolios, NBER Working Paper No. 7795, Cambridge.

Lee, R. and J. Skinner (1999): Will Aging Baby Boomers Bust the Federal Budget? Journal of Economic Perspectives 13, 117-140.

OECD (2002): Education at a glance, Paris.

OECD (2003): Health Data, 4th ed., Paris.

Oeppen, J. and J.W. Vaupel (2002): Broken Limits to Life Expectancy, Science 296, 10291031.

Skinner, J. (1985): The Effect of Increased Longevity on Capital Accumulation, American Economic Review 75, 1143-1150.

Tuljapurkar, S., N. Li and C. Boe (2000): A universal pattern of mortality decline in the G7 countries, Nature 405, 789-792.

United Nations Population Division (2003): World Population Prospects: The 2002 Revision, New York.

Whitehouse, E. (2002): Pension Systems in 15 Countries compared: The Value of Entitlements, Discussion Paper 02/04, Centre for Pensions and Superannuation, Sydney.

Yakita, A. (2001): Uncertain Lifetime, Fertility and Social Security, Journal of Population Economics 14, 635-640. 


\title{
CESifo Working Paper Series
}

\author{
(for full list see www.cesifo.de)
}

1265 Hans-Werner Sinn, Migration, Social Standards and Replacement Incomes. How to Protect Low-income Workers in the Industrialized Countries against the Forces of Globalization and Market Integration, August 2004

1266 Wolfgang Leininger, Fending off one Means Fending off all: Evolutionary Stability in Submodular Games, August 2004

1267 Antoine Bommier and Bertrand Villeneuve, Risk Aversion and the Value of Risk to Life, September 2004

1268 Harrie A. A. Verbon and Lex Meijdam, Too Many Migrants, Too Few Services: A Model of Decision-making on Immigration and Integration with Cultural Distance, September 2004

1269 Thomas Eichner and Rüdiger Pethig, Economic Land Use, Ecosystem Services and Microfounded Species Dynamics, September 2004

1270 Federico Revelli, Performance Rating and Yardstick Competition in Social Service Provision, September 2004

1271 Gerhard O. Orosel and Klaus G. Zauner, Vertical Product Differentiation When Quality is Unobservable to Buyers, September 2004

1272 Christoph Böhringer, Stefan Boeters, and Michael Feil, Taxation and Unemployment: An Applied General Equilibrium Approach, September 2004

1273 Assaf Razin and Efraim Sadka, Welfare Migration: Is the Net Fiscal Burden a Good Measure of its Economics Impact on the Welfare of the Native-Born Population?, September 2004

1274 Tomer Blumkin and Volker Grossmann, Ideological Polarization, Sticky Information, and Policy Reforms, September 2004

1275 Katherine Baicker and Nora Gordon, The Effect of Mandated State Education Spending on Total Local Resources, September 2004

1276 Gabriel J. Felbermayr and Wilhelm Kohler, Exploring the Intensive and Extensive Margins of World Trade, September 2004

1277 John Burbidge, Katherine Cuff and John Leach, Capital Tax Competition with Heterogeneous Firms and Agglomeration Effects, September 2004

1278 Joern-Steffen Pischke, Labor Market Institutions, Wages and Investment, September 2004 
1279 Josef Falkinger and Volker Grossmann, Institutions and Development: The Interaction between Trade Regime and Political System, September 2004

1280 Paolo Surico, Inflation Targeting and Nonlinear Policy Rules: The Case of Asymmetric Preferences, September 2004

1281 Ayal Kimhi, Growth, Inequality and Labor Markets in LDCs: A Survey, September 2004

1282 Robert Dur and Amihai Glazer, Optimal Incentive Contracts for a Worker who Envies his Boss, September 2004

1283 Klaus Abberger, Nonparametric Regression and the Detection of Turning Points in the Ifo Business Climate, September 2004

1284 Werner Güth and Rupert Sausgruber, Tax Morale and Optimal Taxation, September 2004

1285 Luis H. R. Alvarez and Erkki Koskela, Does Risk Aversion Accelerate Optimal Forest Rotation under Uncertainty?, September 2004

1286 Giorgio Brunello and Maria De Paola, Market Failures and the Under-Provision of Training, September 2004

1287 Sanjeev Goyal, Marco van der Leij and José Luis Moraga-González, Economics: An Emerging Small World?, September 2004

1288 Sandro Maffei, Nikolai Raabe and Heinrich W. Ursprung, Political Repression and Child Labor: Theory and Empirical Evidence, September 2004

1289 Georg Götz and Klaus Gugler, Market Concentration and Product Variety under Spatial Competition: Evidence from Retail Gasoline, September 2004

1290 Jonathan Temple and Ludger Wößmann, Dualism and Cross-Country Growth Regressions, September 2004

1291 Ravi Kanbur, Jukka Pirttilä and Matti Tuomala, Non-Welfarist Optimal Taxation and Behavioral Public Economics, October 2004

1292 Maarten C. W. Janssen, José Luis Moraga-González and Matthijs R. Wildenbeest, Consumer Search and Oligopolistic Pricing: An Empirical Investigation, October 2004

1293 Kira Börner and Christa Hainz, The Political Economy of Corruption and the Role of Financial Institutions, October 2004

1294 Christoph A. Schaltegger and Lars P. Feld, Do Large Cabinets Favor Large Governments? Evidence from Swiss Sub-Federal Jurisdictions, October 2004

1295 Marc-Andreas Mündler, The Existence of Informationally Efficient Markets When Individuals Are Rational, October 2004 
1296 Hendrik Jürges, Wolfram F. Richter and Kerstin Schneider, Teacher Quality and Incentives: Theoretical and Empirical Effects of Standards on Teacher Quality, October 2004

1297 David S. Evans and Michael Salinger, An Empirical Analysis of Bundling and Tying: Over-the-Counter Pain Relief and Cold Medicines, October 2004

1298 Gershon Ben-Shakhar, Gary Bornstein, Astrid Hopfensitz and Frans van Winden, Reciprocity and Emotions: Arousal, Self-Reports, and Expectations, October 2004

1299 B. Zorina Khan and Kenneth L. Sokoloff, Institutions and Technological Innovation During Early Economic Growth: Evidence from the Great Inventors of the United States, 1790 - 1930, October 2004

1300 Piero Gottardi and Roberto Serrano, Market Power and Information Revelation in Dynamic Trading, October 2004

1301 Alan V. Deardorff, Who Makes the Rules of Globalization?, October 2004

1302 Sheilagh Ogilvie, The Use and Abuse of Trust: Social Capital and its Deployment by Early Modern Guilds, October 2004

1303 Mario Jametti and Thomas von Ungern-Sternberg, Disaster Insurance or a Disastrous Insurance - Natural Disaster Insurance in France, October 2004

1304 Pieter A. Gautier and José Luis Moraga-González, Strategic Wage Setting and Coordination Frictions with Multiple Applications, October 2004

1305 Julia Darby, Anton Muscatelli and Graeme Roy, Fiscal Federalism, Fiscal Consolidations and Cuts in Central Government Grants: Evidence from an Event Study, October 2004

1306 Michael Waldman, Antitrust Perspectives for Durable-Goods Markets, October 2004

1307 Josef Honerkamp, Stefan Moog and Bernd Raffelhüschen, Earlier or Later: A General Equilibrium Analysis of Bringing Forward an Already Announced Tax Reform, October 2004

1308 M. Hashem Pesaran, A Pair-Wise Approach to Testing for Output and Growth Convergence, October 2004

1309 John Bishop and Ferran Mane, Educational Reform and Disadvantaged Students: Are They Better Off or Worse Off?, October 2004

1310 Alfredo Schclarek, Consumption and Keynesian Fiscal Policy, October 2004

1311 Wolfram F. Richter, Efficiency Effects of Tax Deductions for Work-Related Expenses, October 2004 
1312 Franco Mariuzzo, Patrick Paul Walsh and Ciara Whelan, EU Merger Control in Differentiated Product Industries, October 2004

1313 Kurt Schmidheiny, Income Segregation and Local Progressive Taxation: Empirical Evidence from Switzerland, October 2004

1314 David S. Evans, Andrei Hagiu and Richard Schmalensee, A Survey of the Economic Role of Software Platforms in Computer-Based Industries, October 2004

1315 Frank Riedel and Elmar Wolfstetter, Immediate Demand Reduction in Simultaneous Ascending Bid Auctions, October 2004

1316 Patricia Crifo and Jean-Louis Rullière, Incentives and Anonymity Principle: Crowding Out Toward Users, October 2004

1317 Attila Ambrus and Rossella Argenziano, Network Markets and Consumers Coordination, October 2004

1318 Margarita Katsimi and Thomas Moutos, Monopoly, Inequality and Redistribution Via the Public Provision of Private Goods, October 2004

1319 Jens Josephson and Karl Wärneryd, Long-Run Selection and the Work Ethic, October 2004

1320 Jan K. Brueckner and Oleg Smirnov, Workings of the Melting Pot: Social Networks and the Evolution of Population Attributes, October 2004

1321 Thomas Fuchs and Ludger Wößmann, Computers and Student Learning: Bivariate and Multivariate Evidence on the Availability and Use of Computers at Home and at School, November 2004

1322 Alberto Bisin, Piero Gottardi and Adriano A. Rampini, Managerial Hedging and Portfolio Monitoring, November 2004

1323 Cecilia García-Peñalosa and Jean-François Wen, Redistribution and Occupational Choice in a Schumpeterian Growth Model, November 2004

1324 William Martin and Robert Rowthorn, Will Stability Last?, November 2004

1325 Jianpei Li and Elmar Wolfstetter, Partnership Dissolution, Complementarity, and Investment Incentives, November 2004

1326 Hans Fehr, Sabine Jokisch and Laurence J. Kotlikoff, Fertility, Mortality, and the Developed World's Demographic Transition, November 2004 